\title{
ATTACHMENT STYLES AND DYSFUNCTIONAL ATTITUDES AMONG PATIENTS OF FUNCTIONAL NEUROLOGICAL SYMPTOM DISORDER
}

\author{
Ammara Butt ${ }^{1 \otimes}$, Fatima Saleem², Aysha Rashid', Aamir Hamid ${ }^{3}$, \\ Syed Mohammad Kumail Raza Abdi', Mariam Iftikhar'
}

\begin{abstract}
OBJECTIVE: To explore dysfunctional attitudes and attachment styles of the patients suffering from functional neurological symptom disorder (FNSD) and the relationship between dysfunctional attitudes and attachment styles.

METHODS: This prospective correlational research design was used on a sample of I 50 patients of FNSD enrolled using purposive sampling technique. The study was conducted at Sir Ganga Ram Hospital Lahore, Pakistan from March 2018 until March 2019. For purpose of assessment demographic sheet, Dysfunctional Attitude Scale (DAS) and Revised Adult Attachment Scale (AAS) were used. The results were retrieved using SPSS version 21 .
\end{abstract}

RESULTS: Out of I 50 patients, I 30 (86.7\%) were females \& 20 (13.3\%) were males. The mean age of the patients was $31.35 \pm 9.01$ years. Majority $(n=70$, $46.7 \%)$ were the middle-born children in birth-order. Seventy percent $(n=105)$ were married, $80(53.3 \%)$ had joint family system, 100 (66.7\%) had low socioeconomic status, 95 (63.3\%) had rented residence and I I0 (73.3\%) were from urban areas. Mean duration of education was $7.43 \pm 4.25$ years. Patients of FNSD reported high range of scores on DAS $(187.92 \pm 23.6 \mathrm{I})$. In AAS, highest mean scores were recorded for anxiety attachment style $(26.52 \pm 2.38)$, followed by dependent attachment style $(20.21 \pm 3.03)$. A significant correlation $(r=0.26)$ was noted for DAS with anxiety attachment style ( $p$-value $<0.0$ l)

CONCLUSION: The patients with FNSD exhibit anxious attachment style and high range of dysfunctional attitudes. The anxious attachment style and dysfunctional attitudes are significantly associated with each other.

KEY WORDS: Functional Neurological Symptom Disorder (Non-MeSH); Somatoform Disorders (MeSH); Conversion Disorder (MeSH); Attachment styles (Non-MeSH); Dysfunctional attitudes (Non-MeSH); Dysfunctional Attitude Scale (Non-MeSH); Adult Attachment Scale (Non-MeSH); Psychotherapy (MeSH).

THIS ARTICLE MAY BE CITED AS: Butt A, Saleem F, Rashid A, Hamid A, Abdi SMKR, Iftikhar M. Attachment styles and dysfunctional attitudes among patients of functional neurological symptom disorder. Khyber Med Univ J 2020; I2(3): | 88-9I. DOI: 10.35845/kmuj.2020.19563.

\section{INTRODUCTION}

F unctional Neurological Symptom Disorder (FNSD), previously known as Conversion Disorder (CD), comes under the umbrella of somatic symptom and related disorders. The disorder involves patients experiencing certain medically unexplained symptoms that do not have any neurological basis and which affect the sensory and/or voluntary motor functions of body. Patients with sensory deficits of the disorder comes with the presentation of having impairment and/or inability to see, hear or smell things; whereas, people having motor deficits include symptoms like paralysis or weakness of a part or whole body, impaired speech, difficulty in swallowing, experiencing seizures, tremor or any other abnormal movement, unconsciousness, etc.' In Pakistani psychiatric units and hospitals, FNSD has been reported to be the one of the most common occurring
1. Department of Psychiatry, Sir Ganga Ram Hospital, Fatima Jinnah Medical University, Lahore, Pakistan.

2. Department of Psychiatry, Jinnah Hospital, Lahore, Pakistan.

3. WAPDA Teaching Hospital, Lahore, Pakistan.

Email『: aamirammara@yahoo.com Contact \#: +92-32I-4764374

$\begin{array}{ll}\text { Date Submitted: } & \text { July } 30,2019 \\ \text { Date Revised: } & \text { July } 03,2020 \\ \text { Date Accepted: } & \text { July 05, 2020 }\end{array}$

disorders with the common presentation of episodes of unconsciousness and tremors or jerky body movements. ${ }^{2-4}$ In literature, symptoms of FNSD have also been referred to as: hysteria, psychogenic seizures, non-epileptic attacks, dissociation, medically unexplained symptoms etc. $^{5}$

When a person is born, he forms a special bond with his primary caregivers and gets attached to them in order to receive maximum care and affection. According to attachment theory, in order to maintain healthy and normal social and emotional development, forming a healthy and secure attachment is very necessary. ${ }^{6}$ Meaningful interactions with significant others or people around depend upon the mental representations of an individual. Mental representations, also known as schemas, are developed from the experiences and they have their influence on person's thoughts, emotions and behaviors which in turn influence the current attachments and interactions of an individual. ${ }^{7}$ A pattern of anxious attachment tends to get reflected in personality which plays an important role in understanding the mental health of an individual. ${ }^{8}$ Having an unhealthy and insecure attachment style, interrupt with interpersonal relationships may explains the attention seeking behaviors of the patients with 
TABLE I: QUALITATIVE CHARACTERISTICS OF PATIENTS $(\mathbf{N}=150)$

\begin{tabular}{|l|l|c|}
\hline \multirow{2}{*}{ Characteristics } & Frequency (\%) \\
\hline \multirow{3}{*}{ Occupation } & Male & $20(13.3)$ \\
\cline { 2 - 3 } & Female & $130(86.7)$ \\
\hline \multirow{4}{*}{ Birth Order } & Household & $115(76.7)$ \\
\cline { 2 - 3 } & Private job & $35(23.3)$ \\
\hline \multirow{3}{*}{ Residence } & $\mathrm{I}^{\text {st }}$ born & $25(16.7)$ \\
\cline { 2 - 3 } & Middle born & $70(46.7)$ \\
\cline { 2 - 3 } & Last born & $45(30)$ \\
\cline { 2 - 3 } & Only child & $10(6.7)$ \\
\hline \multirow{3}{*}{ Marital Status } & Own & $55(36.7)$ \\
\cline { 2 - 3 } & Rent & $95(63.3)$ \\
\hline \multirow{2}{*}{ Family System } & Married & $105(70)$ \\
\cline { 2 - 3 } & Unmarried & $40(26.7)$ \\
\cline { 2 - 3 } & Divorced/ Widow & $50(3.3)$ \\
\hline \multirow{2}{*}{ Family Background } & Joint & $70(43.3)$ \\
\cline { 2 - 3 } & Nuclear & $40(26.7)$ \\
\hline \multirow{2}{*}{ Socio-economic Status } & Rural & $110(73.3)$ \\
\cline { 2 - 3 } & Urban & $50(33.3)$ \\
\cline { 2 - 3 } & Lower class & \\
\cline { 2 - 3 } & Middle class & \\
\hline
\end{tabular}

TABLE II: PEARSON PRODUCT MOMENT CORRELATION OF ATTACHMENT STYLES AND DYSFUNCTIONAL ATTITUDES $(N=I 50)$

\begin{tabular}{|c|c|c|c|}
\hline Variable & $\begin{array}{c}\text { Close } \\
\text { Attachment Style }\end{array}$ & $\begin{array}{c}\text { Depend } \\
\text { Attachment Style }\end{array}$ & $\begin{array}{c}\text { Anxiety } \\
\text { Attachment Style }\end{array}$ \\
\hline $\begin{array}{l}\text { Dysfunctional } \\
\text { Attitudes }\end{array}$ & -0.10 & -0.08 & $0.26 * *$ \\
\hline
\end{tabular}

FNSD.

Attitudes are considered to be the integral and the important part of a person's personality. Having dysfunctional thoughts and attitudes lead towards many mental disorders including anxiety, depression, somatic symptoms etc. Dysfunctional attitudes are maladaptive ways of thinking where a person has negative beliefs which are related to self, world and the future. ${ }^{10}$ In Pakistan, FNSD is most likely to be associated with dysfunctional attitudes. 11,12

Researchers have discussed the marked role of dysfunctional attitudes and attachment styles in the course of FNSD. Moreover, the ratio of patients with FNSD is increasing dramatically in Pakistan, therefore, there is need to find that how certain environmental, personal and social factors have an impact on patients with FNSD in our cultural context. Hence, the current excluded. Patients were interviewed by the researcher after taking a written informed consent and were also briefed about the study. Dysfunctional Attitude Scale (DAS) $)^{13}$ was used in order to assess the presence and intensity of maladaptive thought patterns of dysfunctional attitudes. DAS total score is the sum of the 40 -items with a range of 40-280. The higher the score, the more will be dysfunctional attitudes of a person. For measuring attachment styles, Revised Adult Attachment Scale $(A A S)^{14}$ was administrated which measures three attachment styles; close, the degree to which a person is comfortable with intimacy and closeness; depend, the extent to which a person feels that he can depend on others when he is in need and anxiety, which measures a person's worry about being unloved or rejected. Both scales are highly reliable and valid. The results and demographic details were retrieved using SPSS version ${ }^{21}$.

\section{RESULTS}

A total of 150 patients suffering from FNSD were included in the study. The qualitative characteristics of patients are presented in Table I, such as gender, occupation and other variables were presented as frequencies and percentages.

Mean age of patients was $31.35 \pm 9.01$ years. Mean number of children was $2.30 \pm 1.99$ and mean number of siblings was $5.70 \pm 2.78$. Mean duration of education of patients was $7.43 \pm 4.25$ years. Patients reported high range of scores on Dysfunctional Attitude Scale with the mean score of I87.92 $\pm 23.6 I$. On Adult Attachment Scale, results revealed that patients scored high on 'anxiety attachment style' with the mean score of $26.52 \pm 2.38$, followed by dependent attachment with mean score of $20.21 \pm 3.03$, and then finally close attachment with mean score of 13.77 \pm 4.33 .

By applying Pearson Product Moment Correlation, positive significant correlation was found between dysfunctional attitudes and anxiety attachment style $(p$-value $<0.0 \mathrm{I})$ i.e. as dysfunctional attitudes increase, anxiety attachment also increases and vice versa, rest detail are given in Table II. 


\section{DISCUSSION}

The current study was conducted to explore dysfunctional attitudes and attachment styles of the patients suffering from FNSD and the relationship between them. Results revealed that patients exhibit higher dysfunctional attitudes which show the presence and intensity of maladaptive thought patterns. Weich $S$ and colleagues ${ }^{15}$ also found linear associations among high score on the DAS and both the onset and repeat occurrence of episodes of the general psychiatric disorders. Bibi A, et al. ${ }^{2}$ explored that patients with FNSD exceeded the controls on the measure of dysfunctional attitude. It was more prevalent among females; who belong to lower middle socio-economic class than males and those who had higher socio-economic status. According to this study patients scored high on 'anxiety attachment style' which indicates a person's insecurity about being unloved or rejected. Insecure attachment is an important predisposing vulnerability for functional neurological disorders. ${ }^{16}$ Patients with somatic symptoms show anxious attachments that derive from childhood experiences with parental figures. Early exposure to sickness increases the probability that stress will be manifested in somatic symptoms. When suffering from stress as adults, they use bodily complaints to gain care. $^{17}$ Gil FP, et al. ${ }^{18}$ argued that psychopathology does not come directly from insecure attachment, but early childhood affection, family environment, and other social influences may form an individual in a specific way that certain developmental pathways are more likely to be pursued than others. They established the relationship between attachment style and parental bonding in adults with somatic symptom disorders, because of trouble in the early parentchild relationship, a higher than average prevalence of anxious attachment is seen in the patients of somatic symptom and related disorders.

The results of the current study revealed significant correlation between dysfunctional attitudes and anxious attachment style. Reinecke MA and Rogers $\mathrm{GM}^{19}$ found the relationship between attachment styles and dysfunctional attitudes in clinically depressed adults. When an infant experiences threat or fear, he seeks anxious closeness to the caregiver who provides comfort and safety. ${ }^{6}$ Anxious attachment can add to cognitive vulnerability to dysfunctional attitudes. ${ }^{20}$ Roberts JE and associates ${ }^{21}$ suggested that adult's in secure attachment styles are related to dysfunctional attitudes, which in turn predispose to lower level of selfworth. Insecure attachment appears to direct the mental illness in adulthood through its effect on self-worth contingencies and self-esteem.

Although the primary purpose of the study was to examine the relationship between dysfunctional attitudes and attachment styles, the factor of birth order of the patients suffering from FNSD was also evaluated. Research has shown that personality development process is greatly influenced by the birth order, examples are first born, second born, last born and only child. Adler explained that birth order could have a huge influence on a person's life style, which is one's regular way of dealing with his family, society and work etc. ${ }^{22}$ Researchers found the association of birth order with a development of psychopathology including somatic disorders, depressive disorders, anxiety disorders and schizophrenia. FNSD was more common in middle born patients. ${ }^{23}$ The current study also found that FNSD is more prevalent in middle born patients. The study suggested that in order to treat cooccurring issues of mental illness, there is need of more empirical researches on the establishment of dysfunctional attitudes and insecure attachment style, and their influence on psychopathology.

In this study the correlation between demographics and study variables was not found, so further studies should be done to explore the determinants of dysfunctional attitudes and anxious attachment style, on broader level. Moreover, new interventions should be made to encounter dysfunctional attitudes and anxious attachment style among FNSD patients to save them from relapse. Study findings will guide in future to conduct psychotherapy for the patients along with identified areas of specification. However, hospital-based study with a small sample size was a limitation.

\section{CONCLUSION}

It is concluded that patients with FNSD exhibit anxious attachment style and high range of dysfunctional attitudes. The anxious attachment style and dysfunctional attitudes are significantly associated with each other.

\section{ACKNOWLEDGEMENT}

The authors are specially obliged for the efforts of Ms. Sadia Khan (Statistician Lecturer University of Lahore). Her coordination and guidance in statistical analysis is of great worth and without her help it would be difficult for us to complete our work timely.

\section{REFERENCES}

I. American Psychiatric Association. Diagnostic and statistical manual of mental disorders (DSM-5 ${ }^{\circledR}$ ). American Psychiatric Pub; 2013. p.3|8-2|. [Accessed on: July 10, 2019]. Available from URL: https://www.psychiatry.org/psychiatri sts/practice/dsm

2. Bibi A, Masroor U, Iqbal N Dysfunctional attitudes and demographic correlates of patients with conversion disorder; an exploratory study. J Pak Psychiatr Soc 2013;10(1):25-29.

3. Aamir S, Hamayon S, Sultan S. Behavior therapy in dissociative convulsion disorder. J Depress Anxiety 20II; I(I): 1000 I03.DOI: 10.4172/2167-1044.1000103

4. ljaz T, Nasir A, Sarfraz N, ljaz S. Psychometric properties of Conversion Disorder Scale-Revised (CDS) for children. J Pak Med Assoc 2017;67(5):725-30.

5. Lishman WA. Organic psychiatry: The psychological consequences of cerebral disorder. 2nd ed. Oxford: Blackwell Scientific; 1987. p.207-76. [Accessed on: July 10, 2019]. Available from URL: https://www. amazon.com/Organic-PsychiatryPsychological-Consequences Cerebral/dp/06320I4962.

6. Bowlby J. Attachment and Loss: Separation Anxiety and Anger; 1973. p.244-5. [Accessed on: July 10, 2019]. A vailable from URL https://books.google.com.pk/books/a bout/Attachment_and_Loss_Separati on_anxiety_a.html?id=STCXK62k_ik C\&redir_esc $=y$

7. Horowitz LM. Interpersonal foundations of psychopathology. American Psychological Association US; 2004. p.205-56. [Accessed on: July 10, 2019]. Available from URL: 
https://www.apa.org/pubs/books/43 I 7036.

8. Hettema JM, Neale MC, Myers JM, Prescott CA, Kendler KS. A population-based twin study of the relationship between neuroticism and internalizing disorders. Am Psychiatry 2006; I63(5):857-64. DOI: I0.I I 76/ajp.2006.I63.5.857.

9. Noyes R, Stuart SP, Watson DB. A reconceptualization of the somatoform disorders. Psychosomatics 2008;49(I): 14-22. DOI: I0.I I76/appi.psy.49.I.I4.

10. Halvorsen M, Wang CE, Eisemann M, Waterloo K. Dysfunctional attitudes and early maladaptive schemas as predictors of depression: A 9-year follow-up study. Cognit Ther Res 20I0;34(4):368-79.

II. Alvi T, Minhas FA. Type of presentation of dissociative disorder and frequency of co-morbid depressive disorder. J Coll Physicians Surg Pak 2009; 19(2):113-6.

12. Pehlivantürk B, Unal F. Conversion disorder in children and adolescents: clinical features and comorbidity with depressive and anxiety disorders. Turk JPediatr 2000;42(2): I 32-7.
13. Weissman AN, Beck AT. Development and validation of the Dysfunctional Attitude Scale: A preliminary investigation. ERIC 1978. [Accessed on: July I0, 2019]. Available from URL: https://eric.ed. gov/?id=EDI67619.

14. Ravitz P, Maunder R, Hunter J, Sthankiya B, Lancee W. Adult attachment measures: A 25-year review. J Psychosom Res 2010; 69(4):419-32.

15. Weich S, Churchill R, Lewis G. Dysfunctional attitudes and the common mental disorders in primary care. J Affect Disord 2003;75(3):26978.

16. Williams B, Jalilianhasanpour R, Matin $\mathrm{N}$, Fricchione GL, Sepulcre J, Keshavan MS, et al. Individual differences in corticolimbic structural profiles linked to insecure attachment and coping styles in motor functional neurological disorders. J Psychiatr Res 2018;102:230-7. DOI:10.1016/ j.jpsychires.2018.04.006

17. Stuart S, Noyes R Jr. Attachment and interpersonal communication in somatization. Psychosomatics 1999;40(I):34-43. DOI: 10. I0I6/S0033-3 I82(99)7I269-7
18. Gil FP, Scheidt CE, Hoeger D, Nickel M. Relationship between attachment style, parental bonding and alexithymia in adults with somatoform disorders. Int J Psychiatry Med 2008;38(4):437-5I. DOI: 10. 2190/PM.38.4.d

19. Reinecke MA, Rogers GM. Dysfunctional attitudes and attachment style among clinically depressed adults. Behav Cognit Psychother 200I;29(2): 129-4I.DOI: 10. $1017 / 51352465801002016$

20. Williams NL, Riskind JH. Cognitive vulnerability and attachment. J Cognit Psychother 2004; 18(I):3-6.

2I. Roberts JE, Gotlib IH, Kassel JD. Adult attachment security and symptoms of depression: The mediating roles of dysfunctional attitudes and low selfesteem. J Pers Soc Psychol 1996; 70(2):310-20.

22. Eckstein D, Kaufman JA. The role of birth order in personality: An enduring intellectual legacy of Alfred Adler. J Individ Psychol 20I 2;68(I):60-74.

23. Khan MN, Ahmad S, Arshad N. Birth order, family size and its association with conversion disorders. Pak J Med Sci 2006;22(I):38-42

\section{AUTHORS' CONTRIBUTIONS}

Following authors have made substantial contributions to the manuscript as under:

AB: Conception and study design, drafting the manuscript, critical review, final approval of the version to be published.

FS: Acquisition of data, drafting the manuscript, final approval of the version to be published.

AR \& AH: Analysis and interpretation of data, drafting the manuscript, final approval of the version to be published.

SMKRA \& MI: Analysis and interpretation of data, critical review, final approval of the version to be published.

Authors agree to be accountable for all aspects of the work in ensuring that questions related to the accuracy or integrity of any part of the work are appropriately investigated and resolved.

CONFLICT OF INTEREST
Authors declared no conflict of interest
GRANT SUPPORT AND FINANCIAL DISCLOSURE
NIL

\section{DATA SHARING STATEMENT}

The data that support the findings of this study are available on request from the corresponding author. The data are not publicly available due to privacy or ethical restrictions.

(C) This is an Open Access article distributed under the terms of the Creative Commons
Attribution-Non Commercial 2.0 Generic License.

KMUJ web address: www.kmuj.kmu.edu.pk

Email address: kmuj@kmu.edu.pk 